\title{
Severe Crohn's Disease in a HIV-HCv Co-Infected Man
}

Julian Olalla ${ }^{1 *}$, Javier de la Torre ${ }^{1}$, Alfonso del Arco' ${ }^{1}$, Jose M Navarro², Francisco Fernandez ${ }^{2}$, Jose Luis Prada' and Javier Garcia-Alegria1

${ }^{1}$ Hospital Costa del Sol, Unidad de Medicina Interna, Marbella, Spain

${ }^{2}$ Hospital Costa del Sol, Unidad de Medicina Digestiva, Marbella, Spain

Keywords: HIV; Crohn's disease; Adalimumab; HCV

\section{Case Report}

We report the case of a man 47-year-old, with Human Immunodeficiency Virus (HIV) and Hepatitis C Virus (HCV) infection diagnosis since 1998. When he was twenty, he had been intravenous drug user. In November 2006 he had 608 lymphocytes CD4/ $\mu$ l and a viral load of $12.600 \mathrm{cop} / \mathrm{ml}$ of $\mathrm{HIV}$, without antiretroviral treatment (ART), but a HCV viral load of $5.000 .000 \mathrm{UI} / \mathrm{ml}$, genotype 1 and portal hypertension in echography. He began treatment with pegylated interferon (p-IFN) and ribavirin at a dose of $180 \mu \mathrm{g} / \mathrm{week}$ and $1500 \mathrm{mg} /$ day respectively, for his first time, in January 2007. At week 12, the HCV viral load was $185 \mathrm{UI} / \mathrm{ml}$

In December 2007, with 936 lymphocytes CD4/ $\mu$, he showed an intense cutaneous eruption, with fever $\left(38^{\circ} \mathrm{C}\right)$ a dry cough, and was admitted in the hospital. At this point, viral load for $\mathrm{HCV}$ was undetectable. Treatment for HCV infection was stopped and eruption improved, but after a week, he began with diarrhoea with culture, detection of parasites and Clostridium difficile toxin in stools all negatives. Colonoscopy was made, and it showed the presence of deep ulcers, with a biopsy congruent with inflammatory bowel disease, beginning treatment with intravenous steroids. Lymphocytes CD4 rose down to 245 cells/ $\mu$ l and HIV-1 viral load rose up to $43.424 .020 \mathrm{cop} /$ $\mathrm{ml}$. So, ART with tenofovir, emtricitabine, efavirenz and enfuvirtide was instaured. After this, cutaneous lesions got worse and a biopsy of skin was made, with diagnosis of seborreic dermatitis. Four weeks after admittance, the patient had lost $30 \mathrm{~kg}$ of weight and fever continued. PCR test in blood for cytomegalovirus was negative, scan of thorax and abdomen did not showed collections, funduscopy, transthoracic echocardiography, blood and sputum cultures, blood cultures for mycobacteriae and baciloscopies in sputum and urine were normal too. So, capsule endoscopy was made, revealing terminal ileitis with ulcers deep and fibrinous, with a biopsy of Crohn's disease. The patient began treatment with mesalazine, oral corticosteroids, ciprofloxacin and metronidazole, despite ART, and general status improved and fever and diarrhoea disappeared. He was discharged with treatment with mesalazine, oral corticosteroids, emtricitabine, efavirenz and tenofovir.

Two weeks after, he was admitted again because fever and worsening of general status. Parenteral nutrition was instaured and Staphyococcus epidermidis was isolated in blood cultures, beginning treatment with vancomycin (1 gr BID, iv for two weeks). Fourteen days after admission, the patient began to have bloody and intense diarrhoea, with hypotension, and ileostomy was made on day 17 after admission. The patient improved and walked without help, he gained weight and fever disappeared, but bloody and intense diarrhoea appeared again, beginning adalimumab $40 \mathrm{mg}$ weekly was instaured, with an excellent response of the clinical status, fever and diarrhoea. Ten days after, HIV

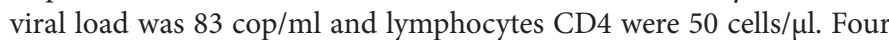
weeks after instauration of adalimumab, the patient presents a sepsis with infiltrate in right lung, and a positive culture in bronquial samples for $E$ coli, with extended spectrum beta lactamases production, that was treated with ertapenem, but the patient died.

\section{Discussion}

There are few cases published about Cronh's disease in the context of treatment with peg-IFN and ribavirin in people with HIV infection [1]. Although anti-TNf- $\alpha$ such etanercept and infliximab have been used safely in a short number of cases in patients with HIV infection [2,3], ours died in the context of sepsis, probably facilitated by the immune depression induced by adalimumab. Peg-IFN has a very high antiviral activity, but has complex immune effects that can lead to exacerbate previous immune disorders. We cannot exclude that Crohn's disease, diagnosed previously to the beginning of ART, was exacerbated in the context of immune reconstitution syndrome, because the very important decrease of viral load in this patient, since the cutaneous lesions worsened after beginning of ART. By the other hand, despite the dramatic decreasing of viral load, lymphocytes CD4 rose down. It has been described in relationship with apoptosis of these cells induced by infliximab [4]. Certainly, the coincidence of severe immune disease with HIV infection leads us to an infrequent scenario, in which each decision must be individualized.

Management of severe autoimmune diseases in people with HIV infection can be very difficult, looking for the balance between immune suppression and infectious complications.

\section{References}

1. Bongiovanni M, Ranieri R, Ferrero S, Casanova F, Monforte A (2006) Crohn's disease onset in an HIV/hepatitis $C$ virus co-infected woman taking pegylated interferon alpha-2b plus ribavirin. AIDS 20: 1989-1990.

2. Linardaki G, Katsarou O, loannidou P, Karafoulidou A, Boki K. (2007) Effective etanercept treatment for psoriatic arthritis complicating concomitant human immunodeficiency virus and hepatitis C virus infection. J Rheumatol 34: 13531355

3. Beltran B, Nos P, Bastida G, Iborra M, Hoyos M, et al. (2006) Safe and effective application of anti-TNF-alpha in a patient infected with HIV and concomitant Crohn's disease. Gut 55: 1670-1671.

4. Filippi J, Roger PM, Schneider SM, Durant J, Breittmayer JP, et al. (2006) Infliximab and human immunodeficiency virus infection: Viral load reduction and CD4+ T-cell loss related to apoptosis. Arch Intern Med 166: 1783-1784.

${ }^{*}$ Corresponding author: Julian Olalla, Hospital Costa del Sol, Unidad de Medicina Interna, Carretera Nacional 340, km 187, 29600. Marbella, Spain, Tel: 607400611 Fax: 00349528282 50; E-mail: olallapombo@telefonica.net

Received December 13, 2011; Accepted June 25, 2012; Published June 28 2012

Citation: Olalla J, la Torre Jd, del Arco A, Navarro JM, Fernandez F, et al. (2012 Severe Crohn's Disease in a HIV-HCv Co-Infected Man. J AIDS Clinic Res 3:157. doi:10.4172/2155-6113.1000157

Copyright: (C) 2012 Olalla J, et al. This is an open-access article distributed unde the terms of the Creative Commons Attribution License, which permits unrestricted use, distribution, and reproduction in any medium, provided the original author and source are credited. 